\title{
Maternal smoking and low birthweight: implications for antenatal care
}

\author{
ROGER J SIMPSON AND N G ARMAND SMITH \\ From the Department of Community Medicine, Odstock Hospital, Salisbury, Wilts
}

SUMMARY The incidence of low birthweight has been related to smoking prevalence in each social group using published data for 1984. The attributable risk of low birthweight has been estimated, based on a relative risk of 2 for mothers who smoke during pregnancy. Assuming $12.5 \%$ of cigarette smokers stopped smoking during pregnancy, $18 \cdot 1 \%$ of all low weight births were caused by maternal smoking in 1984. The percentage for most social groups was similar. The overall attributable risk from smoking was estimated to be $12 \cdot 7$ low weight births per 1000 total births, with a further $12 \cdot 1$ per 1000 due to other factors acting in a socioeconomic gradient. We estimate that the minimum attainable low birthweight incidence in 1984 was 45.4 per 1000 total births, based on the lowest observed incidence, corrected for smoking prevalence, which was in social group II. We recommend the addition of maternal smoking information to the Korner maternity clinical options data set, to enable an accurate assessment of the risks and to provide local monitoring of initiatives to reduce smoking prevalence during pregnancy.

The consequences of maternal smoking on the developing fetus are well established, in terms of both morbidity and mortality. The topic has been reassessed in the latest report on the health consequences of smoking by the Royal College of Physicians. ${ }^{1}$ The prevalence of cigarette smoking among women has decreased from $38 \%$ to $32 \%$ between 1976 and $1984,{ }^{2}$ whereas late fetal and neonatal mortality have decreased much more. This suggests that smoking in pregnancy is now a relatively more important factor in poor outcome.

In 1984, $7 \%$ of total births in England and Wales weighed less than $2500 \mathrm{~g}$. The relative risk of producing a low birthweight baby $(<2500 \mathrm{~g})$ has been shown in several studies to be approximately 2.0 for mothers who smoke. ${ }^{3}$ The risk is independent of the other known risk associations, including previous pregnancy history, parity, maternal height and weight, social class, and race. ${ }^{4}$ The neonatal complications and the later effects on development have been summarised in a recent review of intrauterine growth retardation. $^{5}$

Since smoking is an independent factor, attributable risk can be estimated using the relative risk of low birthweight for smokers. This will give an indication of the number of low weight births which could be avoided by cessation of smoking during pregnancy.

\section{Method}

An assessment can be made of the contribution of maternal smoking to low birthweight incidence using routine data. Smoking prevalence is available for the six categories of the collapsed version of the Registrar General's socioeconomic classification as routine data from the Office of Population Censuses and Surveys (OPCS). ${ }^{2}$ Tables of birthweight for each of the six social classes in 1984 have been published in an OPCS Monitor $^{6}$ but contained errors which were subsequently corrected. ${ }^{9}$ It was assumed that the socioeconomic and social class categories included similar people; the six categories will be termed social groups in this paper. The low birthweight incidence data were linked to the smoking prevalence data for each group. The following assumptions were made:

(a) Relative risk of low weight birth for smokers is 2.0 in each social group.

(b) Smoking prevalence for each group decreases by $12 \cdot 5 \%$ during pregnancy, as estimated by Martin. ${ }^{7}$

(c) There is a minimum risk of low weight birth in the population, which may change over time. Excess risk is due to (i) smoking and (ii) other factors which act in a socioeconomic gradient. 
(d) Differences in the ratio of heavy to light smokers and the average numbers of cigarettes smoked by individuals do not significantly affect the relative risk in each group.

These assumptions are based on information currently available. Subsequent studies may lead to their reappraisal.

The expected low birthweight risk for each social group, if smoking were the only cause, was calculated as follows:

$\begin{aligned} \text { Each group's risk, } R & =(p \times 2 \cdot 0)+[(1-p) \times 1 \cdot 0] \\ \text { Where: } P & \begin{array}{l}\text { estimated proportion } \\ \text { smoking during pregnancy } \\ =\text { smokers' relative risk of } \\ \text { producing a low birthweight } \\ \text { baby } \\ =\text { estimated proportion } \\ \text { non-smoking during } \\ \text { pregnancy } \\ \text { = non-smokers' relative risk }\end{array}\end{aligned}$

The proportion, $\mathrm{p}$, was estimated for each group by reducing the smoking prevalence recorded in the General Household Survey ${ }^{2}$ by $12.5 \%$, that is, multiplying by 0.875 . As an example, the estimated proportion in group IV smoking during pregnancy was $32.375 \%(37 \% \times 0.875)$. The expected risk, $R$, was $(0.32375 \times 2 \cdot 0)+(0.67625 \times 1 \cdot 0)=1.32375$.

If no member of a group smoked, the expected risk, $R$, would be 1.00 for that group. The population's minimum risk was calculated by dividing each group's observed low birthweight incidence by its expected risk, $\mathbf{R}$ (if smoking were the only extra factor). This gave the expected incidence for each group if no member smoked. The lowest resulting incidence occurred in group II, which was therefore used as the population's minimum incidence for 1984. The expected incidence for each group, if smoking were the only excess risk factor, was calculated by multiplying this minimum by each group's expected risk, $\mathbf{R}$. The difference between the resulting expected incidence and the population minimum incidence gave the group's smoking related incidence, which was the attributable risk. The observed incidence minus the expected incidence gave the group's excess incidence due to the other factors.

Unweighed births, non-I to $\mathrm{V}$ births, and illegitimate births were not detailed separately due to lack of data on weight, smoking prevalence or social group. These births comprised $20.96 \%$ of total births in 1984: $0 \cdot 12 \%$ unweighed; $3.52 \%$ not grouped (legitimate); $17 \cdot 32 \%$ not grouped (illegitimate). Some were more likely to be at higher risk of low birthweight, due to several factors, including maternal smoking. The effect on these births, except those unweighed, was taken into account in the total population data.

\section{Results}

The prevalence of cigarette smoking among women in 1984 , the estimated prevalence of smoking during pregnancy (observed prevalence multiplied by 0.875 ), and the incidence of low birthweight are shown in table 1 for each social group.

The estimated smoking prevalence for each group during pregnancy was used to calculate the expected risk, $\mathrm{R}$ (if smoking were the only excess risk factor), which in turn was used to estimate the contribution of smoking to each group's observed low birthweight incidence. Table 2 shows the estimated 1984 population minimum incidence and the expected incidence in each group if smoking were the only excess factor. The estimated smoking related incidence and the excess incidence related to other factors are also shown for each group.

The table shows that the estimated excess incidence of low birthweight due to cigarette smoking varied@ $\omega$ between 6.0 and 14.7 per 1000 total births, depending on the group, with an overall incidence of 12.7 pero $\omega$ 1000. Group I had an excess incidence due to other factors of 5.9 per 1000 , and group $\mathrm{V}$ had an excess of $\overrightarrow{\mathrm{D}}-\overrightarrow{\mathrm{C}}$ 25.7 per 1000 total births. This excess due to other $\frac{\infty}{\infty}$ factors in each group might be caused by differences compared with group II in the distributions of $\frac{\mathbb{D}}{3}$ maternal age, height, parity, alcohol consumption, or any other factors associated with increased risk of low birthweight.

The contribution of smoking and other factors can be calculated from the data in table 2, by applying the estimated incidence rates to the observed number of low weight births in each group. For example, overall 12.7 out of every 70.2 low weight births $(18.1 \%)$ were caused by maternal smoking and 12.1 out of 70.2

Table 1 Smoking prevalence and low birthweight incidence for women in each social group, 1984

\begin{tabular}{llll}
\hline & $\begin{array}{l}\text { \% smoking } \\
\text { cigarettes } \\
\text { in } 1984\end{array}$ & $\begin{array}{l}\text { Estimated \% } \\
\text { smoking during } \\
\text { pregnancy }\end{array}$ & $\begin{array}{l}\text { Observed births } \\
<2500 \text { g per } 1000 \\
\text { total weighed births }\end{array}$ \\
\hline Social group & $15 \%$ & $13 \cdot 125 \%$ & $57 \cdot 3$ \\
II & $29 \%$ & $25 \cdot 375 \%$ & 56.9 \\
III n & $28 \%$ & $24 \cdot 500 \%$ & $59 \cdot 2$ \\
III m & $37 \%$ & $32.375 \%$ & $70 \cdot 5$ \\
IV & $37 \%$ & $32 \cdot 375 \%$ & 83.3 \\
V & $36 \%$ & $31 \cdot 500 \%$ & 85.4 \\
Others* & $?$ & $?$ & 62.3 \\
Illegitimate & $?$ & $?$ & 97.8 \\
All & $32 \%$ & $28.875 \%$ & $70 \cdot 2$ \\
\hline
\end{tabular}

*Others comprise armed forces, unemployed, etc

Source: OPCS Monitors GHS 85/2, DH3 85/5, DH3 86/1 
Table 2 Estimated contribution of cigarette smoking and other excess factors to low birthweight incidence in England and Wales during 1984 (assuming 12.5\% of smokers stopped during pregnancy)

\begin{tabular}{|c|c|c|c|c|c|}
\hline \multirow[b]{2}{*}{ Social group } & \multirow{2}{*}{$\begin{array}{l}\text { Risk } \\
R \\
R\end{array}$} & \multirow{2}{*}{$\begin{array}{l}\text { Observed incidence } \\
<2500 \mathrm{~g} \text { per } \\
1000 \text { total } \\
\text { births } \\
I\end{array}$} & \multirow{2}{*}{$\begin{array}{l}\text { Expected incidence } \\
<2500 \mathrm{~g} \text { per } \\
1000 \text { total } \\
\text { births } \\
(R \times 45 \cdot 4) \\
E^{*}\end{array}$} & \multicolumn{2}{|c|}{$\begin{array}{l}\text { Estimated excess incidence } \\
\text { per } 1000 \text { total births: }\end{array}$} \\
\hline & & & & $\begin{array}{l}\text { Smoking } \\
(E-45 \cdot 4)\end{array}$ & $\begin{array}{l}\text { Other factors } \\
(I-E)\end{array}$ \\
\hline $\begin{array}{l}\text { Population } \\
\text { minimum } \\
\text { incidence }\end{array}$ & 1.00 & & $45 \cdot 4$ & 0 & 0 \\
\hline I & $1 \cdot 13125$ & $57 \cdot 3$ & $51 \cdot 4$ & 6.0 & 5.9 \\
\hline II & $1 \cdot 25375$ & 56.9 & 56.9 & $11 \cdot 5$ & 0 \\
\hline III $n$ & $1 \cdot 24500$ & $59 \cdot 2$ & 56.5 & $11 \cdot 1$ & $2 \cdot 7$ \\
\hline III $\mathrm{m}$ & 1.32375 & $70 \cdot 5$ & $60 \cdot 1$ & $14 \cdot 7$ & $10 \cdot 4$ \\
\hline IV & $1 \cdot 32375$ & $83 \cdot 3$ & $60 \cdot 1$ & $14 \cdot 7$ & $23 \cdot 2$ \\
\hline V & $1 \cdot 31500$ & $85 \cdot 1$ & $69 \cdot 7$ & $14 \cdot 3$ & $25 \cdot 7$ \\
\hline Others & $?$ & $62 \cdot 3$ & $?$ & $?$ & $?$ \\
\hline Illegitimate & $?$ & $97 \cdot 8$ & $?$ & $?$ & $?$ \\
\hline All & $1 \cdot 28875$ & $70 \cdot 2$ & $58 \cdot 1$ & $12 \cdot 7$ & $12 \cdot 1$ \\
\hline
\end{tabular}

*Expected incidence, E, if maternal smoking were the only excess factor

Population minimum incidence $=\frac{56.9}{1.25375}=45.4$

Table 3 Observed low weight births and estimated numbers associated with smoking and other excess social group factors in England and Wales during 1984

\begin{tabular}{|c|c|c|c|c|c|}
\hline \multirow[t]{2}{*}{ Social group } & \multirow[t]{2}{*}{$\begin{array}{l}\text { No. of low weight births } \\
<2500 \mathrm{~g} \text { observed in } 1984 \\
\text { (England and Wales) }\end{array}$} & \multicolumn{2}{|c|}{$\begin{array}{l}\text { Estimated smoking related } \\
\text { low weight births }\end{array}$} & \multicolumn{2}{|c|}{$\begin{array}{l}\text { Estimated excess social group } \\
\text { related low weight births } \\
\text { (Social group II as baseline) }\end{array}$} \\
\hline & & Number & $\%$ of total & Number & $\%$ of total \\
\hline I & 2190 & 229 & $10 \cdot 5$ & 225 & $10 \cdot 3$ \\
\hline II & 6270 & 1267 & $20 \cdot 2$ & 0 & 0 \\
\hline III $n$ & 3280 & 615 & 18.8 & 150 & $4 \cdot 6$ \\
\hline III $\mathrm{m}$ & 12530 & 2613 & 20.9 & 1848 & $14 \cdot 8$ \\
\hline IV & 6080 & 1073 & $17 \cdot 6$ & 1693 & 27.9 \\
\hline V & 2420 & 405 & $16 \cdot 7$ & 728 & 30.1 \\
\hline All births* & 44877 & 8,119 & $18 \cdot 1$ & 7,735 & $17 \cdot 2$ \\
\hline
\end{tabular}

*Weighed births: I-V, Others, and illegitimate

$(17 \cdot 2 \%)$ were associated with other excess factors. The total number of low weight births due to smoking was $8119(18.1 \%$ of total births), the percentage ranging from $10.5 \%$ to $20.9 \%$, as shown in table 3 .

This table shows that smoking was associated with a similar proportion of low weight births in groups II to $\mathrm{V}$, despite the variation in smoking prevalence. This has been shown previously by regression analysis of data from a large birth cohort. ${ }^{8}$ The lower proportion in group I suggests a difference in the effect of smoking, perhaps because of the lower average cigarette consumption of this group. ${ }^{2}$

\section{Discussion}

Smoking in pregnancy gives twice the risk of low birthweight, which in turn is associated with an increased mortality risk. The perinatal mortality rate in England and Wales in 1984 was $10 \cdot 1$ per 1000 total births, and infant mortality was $9 \cdot 3$ per 1000 live births. ${ }^{9}$ In the low birthweight group $(<2500 \mathrm{~g})$, perinatal mortality was 92.6 and infant mortality was 66.8. Maternal smoking not only decreases birthweight but also increases the risk of spontaneous abortion, fetal death, and neonatal death directly with level of cigarette consumption. ${ }^{4}$ There is an increased risk for the mother of abruptio placentae, placenta praevia, early or late bleeding, premature and prolonged rupture of membranes, and preterm delivery. All these complications are associated with high perinatal loss. Risk of pre-eclampsia is decreased by smoking, but if it occurs the risk of perinatal mortality is greatly increased. ${ }^{4}$ A relative risk of 1.28 was found for late fetal and neonatal death in pregnancies subjected to maternal smoking in the British Perinatal Mortality Survey. ${ }^{10}$ This is less than the relative risk of two for 
low birthweight, indicating that the low weight births due to smoking are at less risk of death than the low weight births due to other factors. It has been shown that smoking related low weight births are on average heavier than other low weight births, which may partly explain the different mortality experience. ${ }^{3}$

We have linked published relative risks and routine data in order to estimate the numbers of low weight births that were caused by maternal smoking in 1984 . The assumptions we made have been given in the method section.

The population's minimum incidence of low birthweight in 1984 was estimated to be 45.4 per 1000 total births $(64.7 \%$ of low weight births). We estimated that $12 \cdot 7$ per 1000 total births $(18 \cdot 1 \%$ of low weight births) were associated with maternal smoking; this association has been shown to be causal in several studies. ${ }^{4}$ Some of these low weight births were due to prematurity, since smoking causes $11-14 \%$ of premature births. ${ }^{4}$ The incidence associated with other factors, acting in a socioeconomic gradient, amounted to $12 \cdot 1$ per 1000 total births $(17 \cdot 2 \%$ of low weight births). This excess incidence should not be interpreted as being caused by socioeconomic grouping; the dangers in attributing observations of fetal and neonatal health to social factors have been summarised recently. ${ }^{11}$ The same method was used with 1982 data, the details of which have not been shown in this paper. The estimated 1982 population minimum incidence was $45 \cdot 7$, compared with 45.4 in 1984. The percentage of low weight births attributable to smoking in 1982 was $18.9 \%$, compared with $18.1 \%$ in 1984. Smoking prevalence decreased from $33 \%$ to $32 \%$ between 1982 and 1984 , and so we conclude that the results have not been subject to errors caused by the use of published data generated from samples of births and population.

Disappointingly, recent publications continue to overlook the effect of maternal smoking. One controlled trial on screening for "small-for-dates" babies studied "low risk" mothers using ultrasound examination. ${ }^{12}$ Matching produced $27 \%$ smokers in each group. Therefore a factor giving a relative risk of two was matched in so called "low risk" groups.

Information about smoking behaviour and attitudes is available. A recent national survey showed that $70 \%$ of smokers have tried to stop, of whom half have made at least three attempts. ${ }^{13}$ When questioned, $50 \%$ of the smokers in the survey wanted, and were resolved to try, to give up, while a further $20 \%$ were undecided. Among the ex-smokers, $53 \%$ had found no difficulty in giving up, $41 \%$ had found it easier than expected; $61 \%$ felt better as a result of giving up and $25 \%$ felt no change. ${ }^{13}$ Since the desire to stop smoking seems to be so widespread, we believe all health professionals must take oppportunities to support this. Effective help is available, from individual through to group strategies, and Health District programmes. ${ }^{14}$

Intervention to promote cessation of smoking during pregnancy has been shown to be possible. A large randomised controlled trial in Baltimore, USA, involving 935 pregnant smokers has recently been reported. ${ }^{15}$ The women in the treatment group received regular visits, telephone calls, and information by post to help cessation of smoking. They were required to provide regular feedback about their progress. Evaluation in the eighth month of pregnancy included biochemical assessment using salivary thiocyanate levels. In the treatment group, $43 \%$ had stopped smoking compared with $20 \%$ in the control group. The treatment group's mean birthweight was $92 \mathrm{~g}$ more than that of the control group, statistically significant at the $5 \%$ level. The proportion of births weighing less than $2500 \mathrm{~g}$ was $6.8 \%$ (treatment) and $8.9 \%$ (controls), which was not statistically significant. However, such a reduction could reach the $5 \%$ significance level only in a much larger trial of pregnant smokers. The finding of the British Perinatal Mortality Study ${ }^{10}$ regarding similar $0 N$ outcomes to those for non-smokers if smoking ceasedo ${ }_{0}^{-} \mathrm{W}$ by the fourth month was supported in this study. $\operatorname{In}_{\Omega}$ 음 Britain, the National Perinatal Epidemiology Unit is $\vec{\otimes} \vec{\circ}$ investigating the effect of social support intervention $\frac{\Omega}{D}$ during pregnancy on the subsequent birthweight $\frac{D}{0}$ distribution for mothers already at increased risk of low birthweight. ${ }^{16}$

Table 4 shows our estimates of the effect of increasing non-smoking prevalence during pregnancy? from the 1984 prevalence we have used. This gives an indication of the impact cessation of smoking could have on the numbers of low weight births in England and Wales.

The recent Korner recommendations do not mention maternal smoking in the maternity clinical options data set. ${ }^{17} \mathrm{We}$ recommend the inclusion of this information; it would provide accurate prevalence

Table 5 Estimated annual numbers of low birthweight infants in England and Wales by increasing non-smoking prevalence in pregnancy (based on 1984 figures)

\begin{tabular}{lllll}
\hline \multirow{2}{*}{ Non smoking } & \multicolumn{3}{c}{ Births $<2500 \mathrm{~g}$} & \multicolumn{3}{c}{ prevalence } \\
\cline { 2 - 5 }$\%$ & $\begin{array}{l}\text { Smoking } \\
\text { related }\end{array}$ & $\begin{array}{l}\text { Social group } \\
\text { related }\end{array}$ & Minimum & Total \\
\hline $72.0^{*}$ & 8119 & 7735 & 29023 & 44877 \\
80.0 & 5799 & 7735 & 29023 & 42557 \\
90.0 & 2900 & 7735 & 29023 & 39658 \\
100.0 & 0 & 7735 & 29023 & 36758 \\
\hline
\end{tabular}

*1984 non-smoking prevalence assuming $12.5 \%$ of smokers stopped during pregnancy. 
data which could be linked to the outcome measures already recommended in the Korner minimum data set. It would allow the monitoring of local initiatives to reduce smoking prevalence during pregnancy and demonstrate the improved outcomes that we anticipate.

We thank Dr David Machin, senior lecturer in medical statistics at Southampton University, and Dr David Morris, senior lecturer in community medicine at Newcastle University, for advice and comments. We are grateful to Catherine McGettigan and Nicola Jones for manuscript preparation.

\section{References}

${ }^{1}$ Royal College of Physicians, London. Health or smoking? London: Pitman, 1983.

2 OPCS Monitor General Household Survey GHS 85/2. 'Cigarette smoking 1972-1984. London: HMSO, 1985.

${ }^{3}$ Meyer MB, Bruce SJ, Tonascia JA. 'Pertinatal events Associated with maternal smoking during pregnancy'. Am J Epidemiol 1976; 103: 464-76.

${ }^{4}$ US Surgeon General. 'The health consequences of smoking for women.' US Department of Health and Human Services, 1980.

5 Chiswick ML. 'Intrauterine growth retardation'. Br Med J 1985; 291: 845-8.
6 OPCS Monitor DH3 85/5. 'Birthweight statistics 1984'. London: HMSO 1985.

${ }^{7}$ Martin JC. 'An Overview: maternal nicotine and caffeine consumption and offspring outcome. Neurobehav Toxicol Teratol 1982; 4; 421-7.

${ }^{8}$ Rush D, Cassano P. 'Relationship of cigarette smoking and social class to birth weight and perinatal mortality among all births in Britain 5-11 April 1970'. J Epidemiol Community Health 1983; 37: 249-55.

${ }^{9}$ OPCS Monitor DH3 86/1. 'Infant and perinatal mortality 1984: Birthweight'. London: HMSO 1986.

${ }^{10}$ Butler NR, Goldstein H, Ross EM. 'Cigarette smoking in pregnancy: Its influence on birth weight and perinatal mortality'. Br Med J 1972; 2: 127-30.

11 Chalmers I. 'Short, Black, Baird, Himsworth, and social class differences in fetal and neonatal mortality rates'. Br Med J 1985; 291: 231-3.

12 Neilson JP, Munjanja SP, Whitfield CR. 'Screening for small for dates fetuses: a controlled trial'. Br Med J, 1984; 289: 1179-82.

${ }^{13}$ Marsh A, Matheson J. 'Smoking attitudes and behaviour, An enquiry carried out on behalf of the DHSS and OPCS'. London: HMSO 1983.

${ }^{14}$ Catford JC, Woolaway MC. 'Giving up smoking for life. In: Smith A (ed), Recent advances in community medicine 3, London: Churchill Livingstone 1985: 133-57.

${ }^{15}$ Sexton M, Hebel JR. 'A Clinical trial of change in maternal smoking and its effect on birth weight'. JAMA 1984; 251: 911-5.

${ }^{16}$ Oakley A, Grant A. 'Social support and pregnancy outcome'. In: 'National Perinatal Epidemiology Unit: Report on the unit's work 1981-1984'. Oxford; 1985: 40-1.

${ }^{17}$ DHSS: 'Steering Group on Health Services Information. First Report to the Secretary of State'. London: HMSO 1982: Part 2, Section 6: 45-9. 